\title{
Learning as a key leverage point for sustainability transformations: a case study of a local government in Perth, Western Australia
}

\author{
Jayne Bryant ${ }^{1} \cdot$ Giles Thomson $^{1,2}$ \\ Received: 19 November 2019 / Accepted: 17 April 2020 / Published online: 30 April 2020 \\ (c) The Author(s) 2020
}

\begin{abstract}
This paper presents a case study about embedding sustainability into a local government in Perth, Western Australia, through the introduction of a sustainability policy and the accompanying education and culture change program. This longitudinal case study describes the approach and impact of the program initiated and delivered by internal officers between 2011 and 2016. The use of personal experience, document review and staff interviews present an ethnography of a bureaucracy that casts some light upon the seldom seen inner workings of a local government organisation as it introduced a sustainability program over a period of more than 5 years. The case study provides evidence of the potential power of learning as a key leverage point for transformational sustainability change.
\end{abstract}

Keywords Strategic sustainability $\cdot$ Leverage points $\cdot$ Organisational change $\cdot$ Education for sustainable development . Local government · Leadership

\section{Introduction}

Literature on sustainability transformations often highlights the importance of shifts within large and influential institutions, organisations and businesses to bring about wider societal change (Lotz-Sisitka et al. 2015; Miller et al. 2014; Waddell et al. 2015). The impact and need of such changes is well documented, but less common are descriptions of how this change might actually occur in practice (Macintyre et al. 2018; Perez Salgado et al. 2018). This is especially the case within relatively opaque organisations such as government bureaucracies (Bernstein and Mertz 2011). The purpose of this paper is to attempt to describe a process of organisational change towards sustainability within a local government and relate this to existing theories of change and

Handled by Julia Leventon, Leuphana University, Germany.

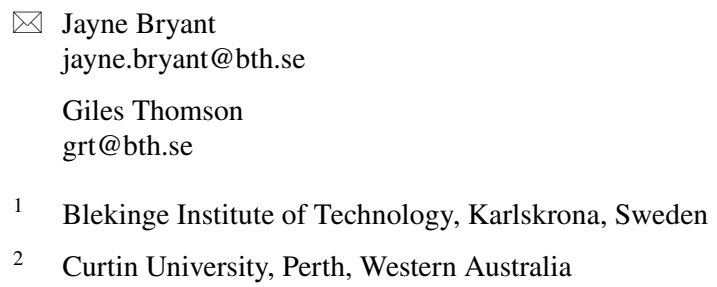

2 Curtin University, Perth, Western Australia

in keeping with this special issue, particularly the concept of 'leverage points' (Abson et al. 2017; Fischer and Riechers 2019; Meadows and Wright 2009). Donella Meadows' (2009) concept of Leverage Points helps identify places to intervene in a system for impactful change. In addressing the unsustainable trajectory of our society, Abson et al. (2017, p. 30) suggest "there is an urgent need to focus on less obvious but potentially far more powerful areas of intervention" and proposes to group the 12 leverage points identified by Meadows into four realms ranging from the shallowest to deepest leverage, they label these realm: parameters, feedbacks, design and intent. This paper focuses on intent, the deepest leverage point, which relates to changing the goals of the system, and changing mind-sets and paradigms (Abson et al. 2017; Fischer and Riechers 2019).

Learning represents one such powerful area of intervention as it is capable of shifting values and ultimately, through human agency, system intent. The power of learning as a key leverage point for societal transition towards sustainability has been previously described (Barth 2015; Missimer and Connell 2012; Rieckmann 2012); however, the value and potential contribution of education in sustainability transformations is undervalued as evidenced by our continued focus on technical fixes and standardised "smart" solutions. Education still holds much underutilised potential (Barth 
and Michelsen 2013). Learning in its deepest sense could be argued to be a process whereby people transform or 'transcend paradigms' and see the world anew (Meyer and Land 2005; Mezirow 1997), and thus learning is a key leverage point to shift institutions towards sustainability.

The organisational change process as described here uses an internal learning program grounded in a 'strategic sustainability' approach (see Broman and Robèrt 2017) and could be tailored to suit many other similar organisations. This paper considers the role of education as a leverage point within large organisations, specifically a local government.

Municipalities or local governments are organisations that have considerable societal impact and influence, and thus represent a key opportunity for sustainability transformations. They are traditionally conservative institutions and resistant to change because of their deeply embedded regulatory and cultural structures. Yet institutions are made by, and comprise, human beings who have the capacity to learn, grow, change and who may even choose to lead sustainability initiatives. Typically, sustainability officers in the local government sector implement sustainability projects themselves (e.g. putting solar power on government buildings). These technical interventions, while highly tangible, are essentially shallow leverage points. In this case study, a sustainability policy and education program in a local government is described, whereby the goal was to find deep leverage points with the aim to shift the intent of the organisation by building the capacity of staff, individually and collectively, to make change for sustainability. Such an approach aligns with the leverage points view that a small shift in a complex system may lead to fundamental changes in the system as a whole, with many actors amplifying sustainability impact (see Fig. 1). Each trained staff member
(Sustainability Champion) could then go and use this sustainability capacity to implement change within their own field of influence amplifying impact (see Table 2 for the learning interventions and Table 3 for tangible examples of outcomes of the staff education).

\section{Background: local government in Australia}

To better explain the organisational environment of the City of Canning, it is useful to position it in the broader geographical and governmental context. The City of Canning (Canning) is not a 'city' as such, rather it is a local government area in Perth, Western Australia. Perth is home to two million people administered through 30 local governments in the metropolitan area. Canning is a relatively large local government by Perth standards covering $64.8 \mathrm{~km}^{2}$ with around 100,000 residents.

Australia has three tiers of government-national, state and local. No federal jurisdiction exists over local governments in Australia, instead each of the six states and two territories delegates authority to smaller local government organisations through a state-based local government legislation that covers roles and responsibilities, codes of conduct and other procedures.

Yet, local government remains to many people an opaque monolith with obscure inner workings. Figure 2 illustrates the key components of an Australian local government. The elected members sometimes referred to collectively as 'the Council' are the community facing political component of the local government. They comprise the governing board responsible for strategic direction and major decisions. 'The administration' or the bureaucracy comprises professional staff, known as 'officers' who have varying levels of
Fig. 1 Learning as a key leverage point: amplifying impact and shifting institutional intent through learning and capacity building of staff (Adapted from Abson et al. 2017; Fischer and Riechers 2019)

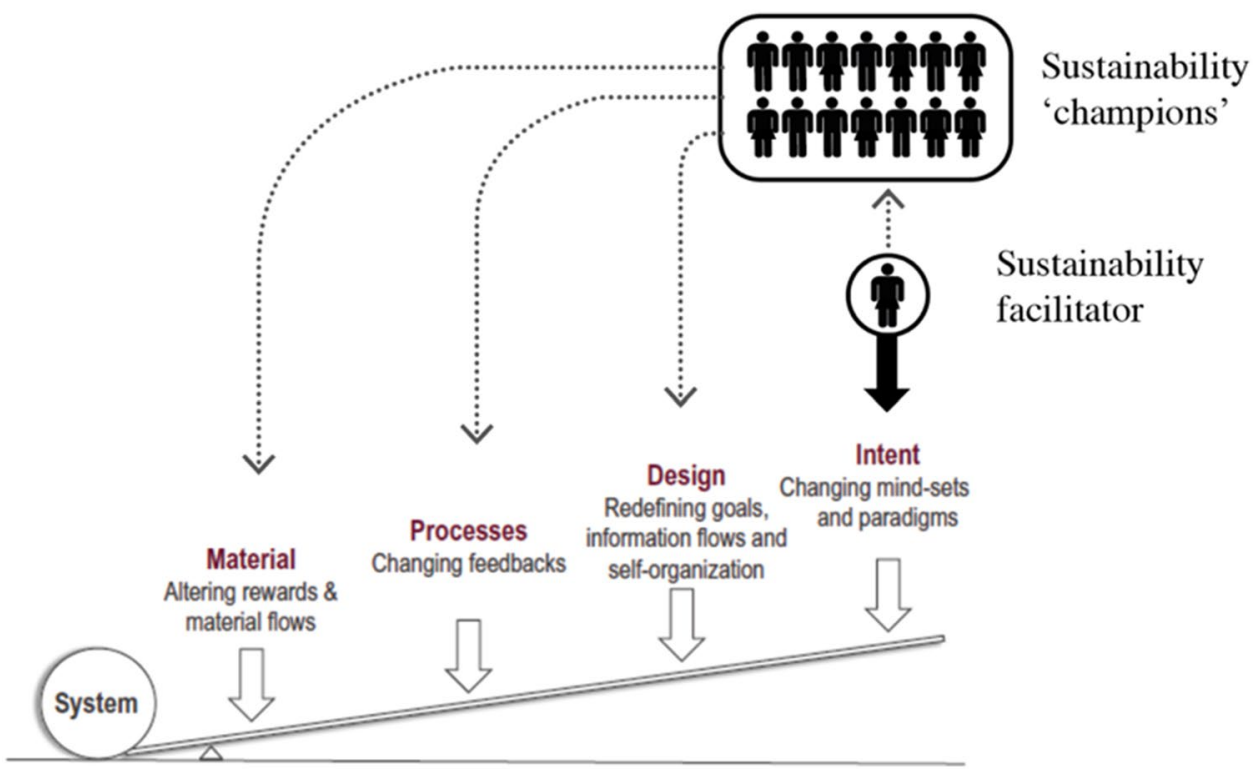




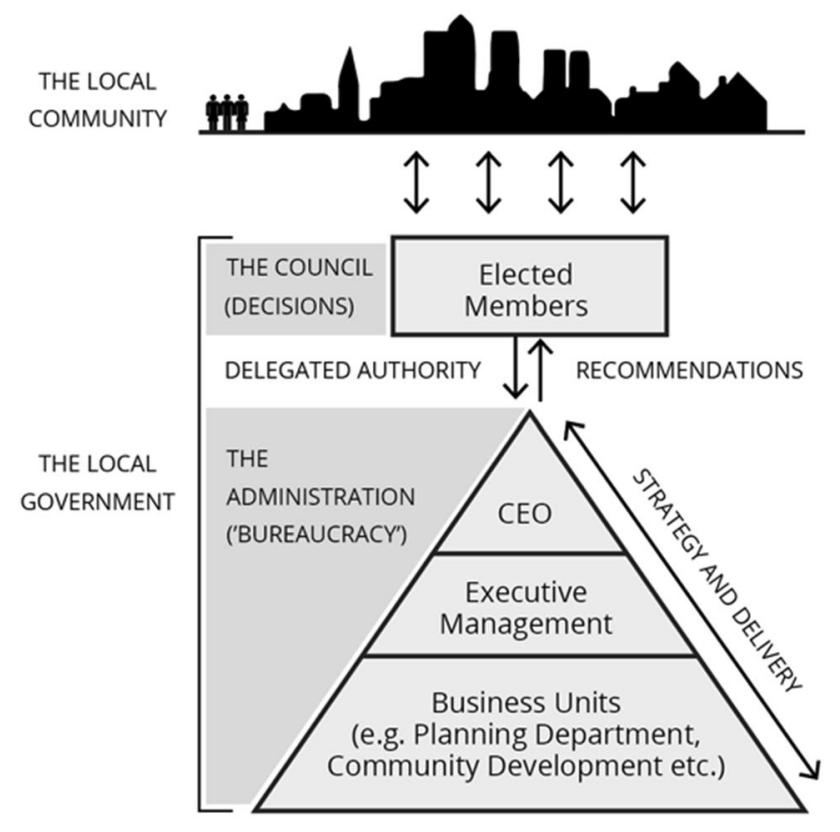

Fig. 2 Conceptual diagram showing the high-level composition of local government in Australia

delegated authority, the Council determines this authority which 'flows down' to officers allowing them to make decisions and carry out duties (e.g. formulating strategies or delivering services). Information also 'flows up' from the officers to the Council in the form of recommendations to be voted upon, and in this sense officers have soft power to influence decisions.

Only policy decisions ratified by the elected members are officially communicated to the public - this single voice of the administration perpetuates the image of the monolith, but the reality inside the administration is another story-like any organisation it is made up of humans. These officers comprise a cross-section of society: they include managers and workers, a range of professional officers such as economists, ecologists, planners, gym instructors, gardeners, librarians and community social workers. A mass of life exists within the administrative monolith, and this case study presents a change management process that emerged from within the administration of Canning. At the time of this case study, there were 1200 full-time equivalent staff employed as officers within the administration, each with agency.

\section{Methods and approach}

This case study offers a narrative account of an organisational change process within Canning over a 5-year period. It was not originally designed as a research study but rather it seeks to tell the story of 'bureaucrats in the bureaucracy' as participants in a complex social systemthe local government administration-and in this story the goal was to embed sustainability within the organisation. In this sense, the authors acknowledge their privileged position as both academics and Canning employees at various times over the narrative period. According to Yin's (2013) categorisation of case studies, this single case study is both revelatory and longitudinal.

It is a revelatory case study, in that it reveals something that is not easily accessible or studied; as Bernstein and Mertz (2011) describe the need for more ethnography of bureaucracies to explore the hidden realm of government institutions: "Scholars looking at the negotiation of power in state institutions often focus on situations with clear one-way flows and monologic communication-speeches, announcements-where one can distinguish the voices and the persons representing the state to its people... Few people investigate the main occupations of contemporary states: administration, regulation, delegation" (Bernstein and Mertz 2011, p. 6). They continue: "Actual bureaucrats in actual bureaucracies, just like people in all sorts of other settings, constantly make decisions, interact with others, exceed their own control. As a lived social world, the administrative setting is not as drab and lifeless as it appears from the outside" (Bernstein and Mertz 2011, p. 7).

It is also a longitudinal case study, covering an educational change management program from mid-2011 through 2016. During this period, the primary author progressed through several relevant employment roles within the local government administration, originally as a Strategic Projects Officer, which through internal lobbying became the Sustainability Facilitator and then Sustainability Coordinator (with a Sustainability Officer position hired to assist). The second author was both employed within and then research collaborator to Canning from 2014 to 2016. In this sense, we (the authors) relate to Bernstein and Mertz (2011) notion of "ethnographers of bureaucracies". This case study describes the experience of the authors from within the bureaucracy, including the actions of the primary author as Sustainability Facilitator in leading the sustainability education programs, policy change as well as the numerous other actors that catalysed internal organisational change over the study period. In addition to this approach, a follow-up survey was conducted in 2019 providing an 8-year window of insight into the organisation. In preparation of this paper, relevant documents from the administration were reviewed including the sustainability policy, the website, and a number of reports describing the sustainability activities and reporting over the study period, and a 2016 report prepared by an independent consultant on sustainability initiatives within Canning. 


\section{Background study}

The primary authors' thesis "Being Human in the System: A journey into sustainability and local government in Perth, Western Australia" was treated as a background study. The thesis was prepared by the primary author of this paper in 2011-2012 as a part of a Master's Degree in Human Ecology at Lund University, Sweden, while also employed as a Strategic Projects Officer at Canning. The background study describes sustainability initiatives and opportunities within the municipality, as well as identifying the enablers and barriers in moving Western Australian local governments towards sustainability. Critically, in the few years before the background study was written, the Western Australian Government had introduced a State Sustainability Strategy (SSS) (Western Australia 2003) as a framework to promote sustainability in local government. The SSS led to a revision of the Western Australian Local Government Act (1995) through the introduction of an Integrated Planning and Reporting Framework (IPRF) (2010) requiring all local governments to conduct participatory community planning processes and show how this process linked to the creation of local sustainable communities. The background study (thesis) reviewed some of these processes using participant observation, document analysis, surveys of local government officers (16 respondents) and nine in-depth interviews with local government councillors, mayors and officers from three different councils in Perth: The Cities of Fremantle, Vincent and Canning. The results of this research used the Leverage Points concept to understand how sustainability was being integrated into Perth municipalities and to identify opportunities for places to make change within the local government system. This work informed a number of the approaches applied in the subsequent years as described in the Theoretical Frameworks section below.

\section{Evaluation of sustainability program}

To understand the impact and legacy of the work, a followup survey was conducted in 2019 to complement the document analysis and the ethnographic approach. The survey was completed by 20 current and previous employees from across the organisation who were a part of the sustainability program at the City of Canning, one of which was the Sustainability Lead 2017-2018; another who was the Sustainability Lead at the Canning from 2018 and held the role at the time of the evaluation; and the Sustainability Officer who has been at the City of Canning the whole case study period and was in the role at the time of evaluation. Participants were asked to share their reflections on the program, and specifically to focus on the following: the key interventions, the key relationships or human elements, the education and training program and the legacy and impact that remains.
Survey responses shaped the following sections, and direct quotes from survey participants have been incorporated throughout the text.

\section{Theoretical frameworks}

Two complementary theoretical frameworks guided the thinking and approach in this organisational change program: Leverage Points (Meadows and Wright 2009) and the Framework for Strategic Sustainable Development (FSSD) also known as The Natural Step (TNS) (Robèrt et al. 2002).

The background study from 2011 to 2012 predated the sustainability program at Canning. The purpose of the study was to identify which Leverage Points (Meadows and Wright 2009) might be most effective in bringing about change in an Australian local government. The study acknowledged a range of possible Leverage Points_-“...places of power for change within the system... From taxes and subsidies (leverage point 12) to promote solar power PV cells for the community, or increasing the transparency and accessibility of the information within the system (leverage point 5). New laws and legislations such the Carbon Tax, or the Integrated Planning and Reporting Framework can have a big influence on the system (leverage point 3). Effective community engagement and a more deliberative democracy approach can be powerful places to change (leverage point 4)" (Bryant 2012, p. 47). But critically it identified that "... educating people about the how local government works, and making it more accessible to the general population is essential in us creating a more effective and sustainability-enabled system in Perth" (Bryant 2012, p. 49). In keeping with Abson et al. (2017) the background study identifies the deepest leverage point as "... the human being within the system, the one that creates the system is recognized as the most powerful place of change. The human's ability to recognize, change and transcend paradigms is the most effective lever to effect change" (Bryant 2012, p. 48).

The Leverage Points concept (Meadows and Wright 2009) framed the need to shift the paradigms within which the organisation operates: the communication and information flow, the structures and systems that guided action, and the places of delegated authority and leverage. It outlined the need to energise and empower the people within the organisation to operate on all levels of the system for sustainable change and used collaboration and learning as a pathway to achieve this. Critically, the Leverage Points perspective brings in the human element of change within a system by highlighting teleology - the goals or thinking of the humans governing the system (Fischer and Riechers 2019).

This brings us to the second theoretical framework-the Framework for Strategic Sustainable Development (FSSD). The FSSD provides a way to navigate complexity and move towards sustainability in a strategic and collaborative way, 
through a shared definition and a systematic approach. The key components of the FSSD (Robèrt et al. 2002) include the following:

- A funnel metaphor facilitating an understanding of the sustainability challenge and benefits of action towards sustainability;

- A five-level model for structuring and clarifying the inter-relationships in complex systems (e.g. organisations);

- A principled definition of sustainability useful as boundary conditions for backcasting planning and redesign for sustainability; and

- An operational procedure (known as the "ABCD" process) which facilitates creative co-creation of strategic transitions towards sustainability (see Broman and Robèrt 2017 for a detailed explanation of the FSSD approach).

Also known by many as The Natural Step Framework, the FSSD is a holistic and systems thinking approach that has evolved through collaboration between businesses and scientists over the past three decades with the expressed aim to support organisations move towards sustainability. It has been used by numerous organisation (e.g. IKEA, Volvo, Electrolux) and many local governments particularly in Sweden and Canada (Broman and Robèrt 2017). Various sustainability models, approaches and frameworks could have been chosen for this work, but the FSSD developed by Robert (2002) with its strategic and system-based approach was chosen for Canning. It was used as the foundation for the education and training program, the principles for the Sustainability Policy, and the "ABCD" strategic planning workshops for the Departmental Action Plans (see Table 2 for more on this). Most significantly, the FSSD provided a shared language, definition and framing of Sustainability to align activities within the organisation.

\section{Case study: sustainability program 2011- 2016}

The sustainability initiatives at Canning which began in 2011 emerged from within the administration, not from a Mayor or Council. This is in stark contrast to stereotypical accounts of the machinations of bureaucracies. Although many of Canning's operations could be framed as sustainability, in 2011 there was no position statement, no mention on the Canning's website, no policy, strategy or human resource dedicated to deliver sustainability. The baseline for this study was summed up by one respondent from the 2019 evaluation survey:
"There was no common will toward sustainability prior to the program or even a common set of knowledge or teleology of sustainability existing."

The case study coincided with a very tumultuous leadership period. Over 5 years from 2011 to 2016, the City of Canning experienced continuous change, including four different Chief Executive Officers (one Acting CEO); two completely different Councils; two sets of Commissioners; investigation of the Council and Administration and ultimately suspension of the Council; Local Government Reform which would see the Canning being cut into four pieces and cease to exist as an entity; and then cancellation of the Local Government Reform by the State Government. With all of this change at the top decision-making level, consistent, long-term decision-making was next to impossible for Canning. By comparison, the administration remained relatively stable, and to some degree this resilience is unsurprising because the values, procedures and direction of the administration are embedded in the institutional instruments and policies that give the administration direction.

The following sections attempt to untangle the sometimes 'messy' inner workings of the bureaucracy (Lyles 2014) and describe some of the key steps in the change process.

To provide some structure to the messiness, the following Fig. 3 provides a high-level overview of the sustainability program and the context.

The following sections provide further description around these major events focussing on:

- People: the humans in the system - the agency of internal actors within the bureaucracy.

- Policy: institutional instruments used to embed sustainability into the organisational structure and processes.

- Education Program: learning together as a key leverage point explains the methods used which build organisational capacity for further impact.

- Sustainability initiatives: the interventions and impacts of the Sustainability Champions and Representatives and Green Teams.

\section{People: the humans in the system}

It was an informal email to all staff by the primary author in a new role (Strategic Projects Officer) in the recently created City Futures department in 2011 that began the journey. The email went to the whole administration inviting anyone who wanted to be a part of creating a more sustainable Canning to come and meet for a cup of tea. This became a regular event every couple of months with several people (6-15) joining for informal meetings over the following year, all voluntarily and in addition to their regular work. It was not until 2013 that a formal Sustainability Facilitator position was created, 


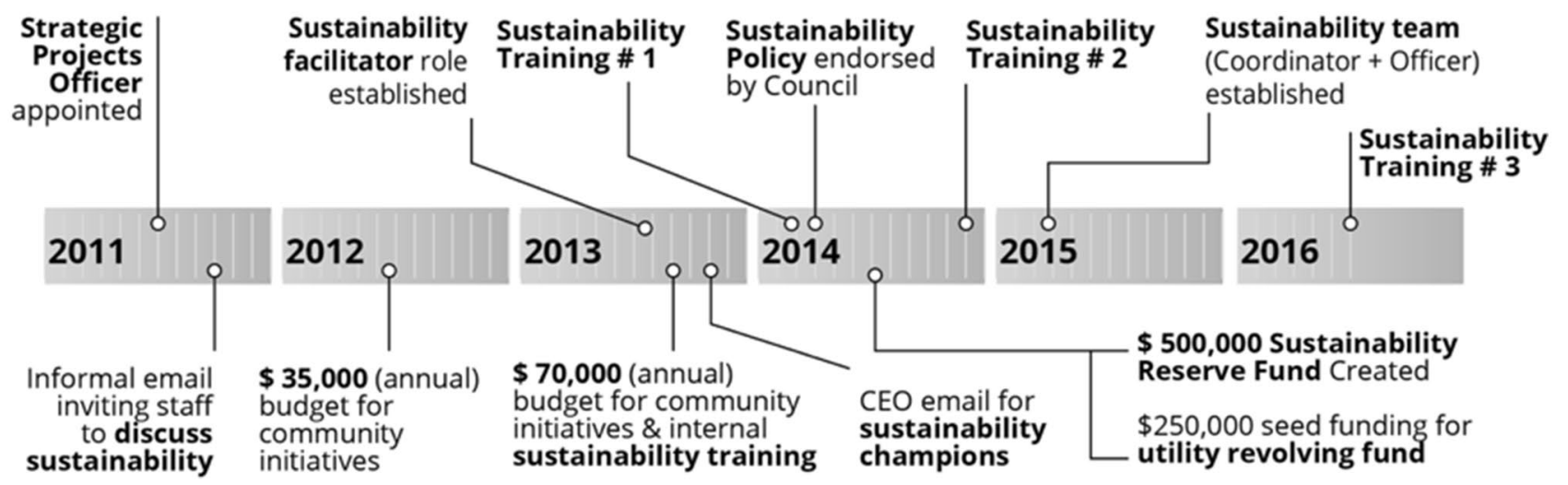

Fig. 3 Summary of key events in the creation of a Sustainability Program at the City of Canning 2011-2016

and an email invitation from the new CEO formalised the 'Sustainability Champion' group. Most of the original participants become a part of this cross-organisational group headed by the Sustainability Facilitator. The newly formed Sustainability Champions (Champions) group met regularly—about once a month—and were budgeted to work 4 $\mathrm{h}$ a week on improving the sustainability within their work and team. They shared knowledge and research on ways to approach sustainability within local government. There were many other local governments that had sustainability strategies, goals or policies but usually positioned alongside or beneath the local government's core strategic planning documents (e.g. an Environmental Plan or Strategy). The Champions saw embedding sustainability into the core organisational systems as the goal.

The approach was collaborative, and the solutions were co-designed, but the responsibility rested with the Sustainability Facilitator to report to the Director City Futures and the Executive Management. The Director of City Futures was an active designer, supporter and champion of the program. This support and the importance of the relationships within the organisation to make change is identified in one of the 2019 survey respondents: "having relationships with people across the organisation and higher in the hierarchy was also very important to ensure initiatives were supported". This supportive leadership which created the space for a junior staff member to lobby for and create a coalition of change for sustainability could be referred to enabling leadership and is essential for co-creating solutions to complex problems in complex systems such as organisations (Uhl-Bien et al. 2007).

Another respondent from the survey identified the collaborative approach to defining the problem and creating solutions as key to creating impact: "the participatory approach that involved everyone on the journey to sustainability was also important in embedding change".
The following Table 1 gives an account of the key human resource roles actors that drove the processes of change within the administration over the case study period.

\section{Policy: institutional instruments}

The sustainability team and Champions were seeking ways to embed sustainability into the organisation and identified a sustainability policy as an essential tool to support the change. Written by the Sustainability Facilitator and the Director City Futures, the Sustainability Policy mandated an integrated approach to embed sustainability into core council processes through the Integrated Planning and Reporting Framework (e.g. sustainability actions were required in each department's Business Unit Plans, Departmental Workshops created Sustainability Action Plans), and into decision-making tools such as the Council Reports. It also mandated the training and capacity building of staff to achieve this.

The policy blended the Brundtland (1987) definition of sustainable development with the FSSD sustainability principles to guide decision making. It is captured in this extract from the Sustainability Policy's objective “.... journey towards development that meets the needs of the present without compromising the ability of future generations to meet their own needs and is achieved by developing policies and practices that ultimately meet the sustainability principles". The four sustainability principles of the FSSD were included as part of the Sustainability Policy (2014) which required staff within the organisation to work towards reducing and eventually eliminating:

(1) Fossil fuel dependence and wasteful use of scarce metals and minerals;

(2) Reliance upon persistent chemicals and wasteful use of synthetic substances; 
Table 1 Key human resource roles within the Sustainability Program

\begin{tabular}{|c|c|}
\hline Role & Position \\
\hline Director City Futures & $\begin{array}{l}\text { Department director for strategic planning and community engagement, executive 'sponsor' of the sustainability } \\
\text { team }\end{array}$ \\
\hline Sustainability Facilitator/Team & $\begin{array}{l}\text { A full-time permanent Sustainability Facilitator position was created in } 2013 \text {, and an Officer role was created in } \\
\text { late } 2014 \text { with the new financial resources Sustainability Reserve Fund }(\$ 500 \mathrm{~K}) \text {. It became a permanent posi- } \\
\text { tion in December } 2015 \text {. This team led the sustainability change process at the City }\end{array}$ \\
\hline Sustainability Champions & $\begin{array}{l}\text { At first this term was used to identify the group who volunteered through CEO invitation to be a part of the } \\
\text { team supporting sustainability change, and who underwent Strategic Sustainability Training. As the move- } \\
\text { ment grew, it was used to identify any staff member who wanted to be a champion for sustainability and had } \\
\text { completed or intended to undergo the training }\end{array}$ \\
\hline Sustainability Representatives & $\begin{array}{l}\text { Each Department had a Sustainability Representative to support the Manager of the Department prepare a } \\
\text { Departmental Sustainability Action Plan and sustainability aspects of the Business Unit Plan. There were } \\
21 \text { Departments (or Business Units) within the organisation, each with a Manager who was responsible } \\
\text { for a Business Unit Plan, and associated budget for operations and delivery of services. The Sustainability } \\
\text { Policy required all Business Plans to address the sustainability principles by proposing departmental actions. } \\
\text { Sustainability Representatives were appointed by their Manager and were in many cases Champions who had } \\
\text { undergone Strategic Sustainability training }\end{array}$ \\
\hline Green Teams & $\begin{array}{l}\text { Some departments had more than one Champion or Representative, and these groups formed Green Teams and } \\
\text { worked together on actions and raising awareness within their departments and communities they served (e.g. } \\
\text { Aged Care Services held 'Plastic Free Morning Tea' for their community) }\end{array}$ \\
\hline
\end{tabular}

(3) Encroachment upon nature (e.g. land, water, wildlife, bushland, soil, ecosystems);

(4) Conditions that systematically undermine people's ability to meet their basic human needs. (Sustainability Policy CM194, Adopted at the Ordinary Council Meeting 18/3/2014 CR-012-14).

The education program, described in the next section, was designed to help staff achieve this.

\section{Education program: learning together as a key leverage point}

In transdisciplinary research, the need for shared understanding of concepts is well documented (Lang et al. 2012). The role of educational science and the importance of learning in this process is an undervalued function (Barth and Michelsen 2013). In this case, the training of the Champions in the FSSD provided a shared language to aid collaboration. Of the education program, one survey respondent said: "It was very important as it helped people grasp a concept that can be interpreted in different ways, is nebulous and complex. Education provided an opportunity to 'talk the same language' when addressing sustainability_people could see how it relates to their work and how they can changeempowered people to act and share the sustainability beyond their group."

This shared language and understanding helped create an environment where people could work across traditional disciplinary boundaries. Boundary spanners refer to individuals who act as a bridge between fields, who develop "effective relational and interpersonal competencies to develop mutual understanding, trust and respect" (Bögel et al. 2019, p. 361). The appointment of the Sustainability Facilitator by a supportive CEO resourced a boundary spanner (Bögel et al. 2019) to work vertically across hierarchical levels of the organisation (i.e. engaging with the CEO, Elected members, department managers, officers and workers), and horizontally across departmental silos to generate interest within the organisation, and finally coach, empower and educate others to become Boundary Spanners. The importance of this was highlighted by one of the survey respondents for:

“...it's 'multi-pronged' approach to embed sustainable thinking:

(1) Top down, working with council and executive to build support and understanding

(2) The bottom up among staff with casual and formal learning, capacity building and project reflection/ reporting in and

(3) Community aspects that both allowed the community to inform the city, and education to the community."

The application of this dedicated Sustainability Facilitator to offer training and to co-ordinate networks and meetings provided a level of curated and integrated interaction that would be unlikely to result from one off (internal or external) training. To this extent, the training set the foundations upon which to build a co-ordinated network of change agents within the organisation who could mutually support each other and learn together. 


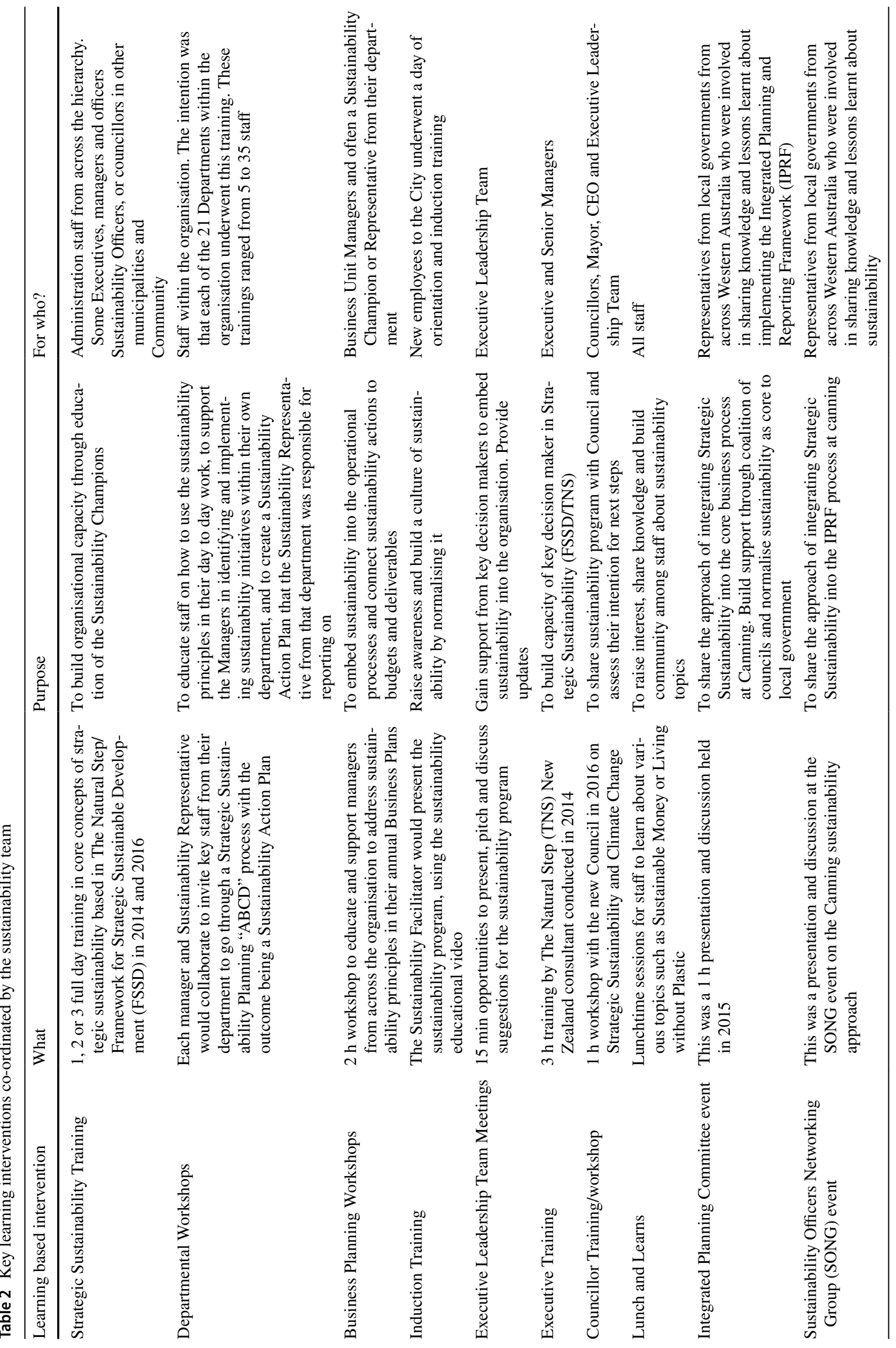



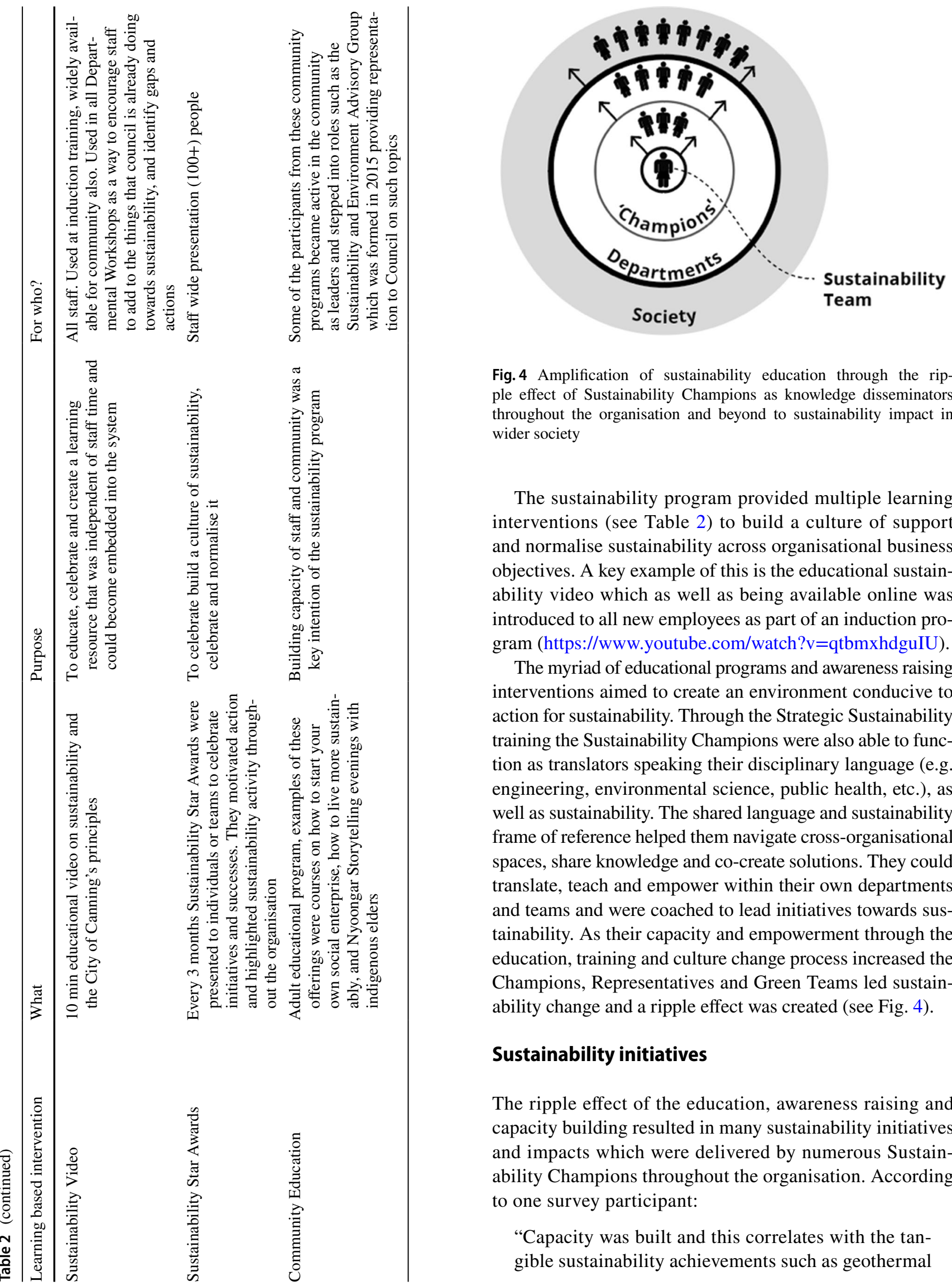

Fig. 4 Amplification of sustainability education through the ripple effect of Sustainability Champions as knowledge disseminators throughout the organisation and beyond to sustainability impact in wider society

The sustainability program provided multiple learning interventions (see Table 2) to build a culture of support and normalise sustainability across organisational business objectives. A key example of this is the educational sustainability video which as well as being available online was introduced to all new employees as part of an induction program (https://www.youtube.com/watch?v=qtbmxhdguIU).

The myriad of educational programs and awareness raising interventions aimed to create an environment conducive to action for sustainability. Through the Strategic Sustainability training the Sustainability Champions were also able to function as translators speaking their disciplinary language (e.g. engineering, environmental science, public health, etc.), as well as sustainability. The shared language and sustainability frame of reference helped them navigate cross-organisational spaces, share knowledge and co-create solutions. They could translate, teach and empower within their own departments and teams and were coached to lead initiatives towards sustainability. As their capacity and empowerment through the education, training and culture change process increased the Champions, Representatives and Green Teams led sustainability change and a ripple effect was created (see Fig. 4).

\section{Sustainability initiatives}

The ripple effect of the education, awareness raising and capacity building resulted in many sustainability initiatives and impacts which were delivered by numerous Sustainability Champions throughout the organisation. According to one survey participant:

"Capacity was built and this correlates with the tangible sustainability achievements such as geothermal 
Table 3 Example of sustainability initiatives

Action Description

Organisation wide

Utility Revolving Fund-to invest in water and energy efficiency

Financial savings (around AU\$120,000/year) resulting from these investments are returned to the Fund to provide for further efficiency improvements and ensuing financial sustainability. The Utility Revolving Fund has resulted in:

Installation of solar hot water units in City buildings; Installation of solar panels on City buildings;

Installation of water efficient showerheads and taps at the Cannington and Riverton Leisureplex' and Civic and Administration Centre

LED lighting upgrade at the Riverton Leisureplex and the Civic and Administration Centre Carpark

Modifications to the timing of air-conditioning within the Civic and Administration Centre

Construction services

Resource reduction
Asphalt for new roads and resurfacing contain a minimum of 5-7\% recycled container glass and $10 \%$ recycled asphalt

Use of $100 \%$ recycled road base

Use of concrete tyre baled retaining walls

Use of warm mix for asphalt instead of hot mix reducing energy consumption by $35 \%$

Information services

Energy efficiency

Resource reduction
Default power saving settings on all computers

Global default printing settings to double sided in black and white Increased desktop PCs life from 3 to 4 years

Extended monitor life cycle

Loan laptops for meeting rooms

Care Services Department (includes disability and aged care housing and support)

Waste reduction

Vertical gardens and implemented

Energy efficiency
Composting bins

Recycling bins

Air conditioning systems readjusted to switch off after hours

Leisure Facilities Department (manages the community swimming pools and gyms)

Transport

Energy efficiency

Renewable energy

Water efficiency

Planning services

Paper reduction
Purchased bicycle fleet for staff transport

Centres certification (see utility revolving fund above)

Amended air conditioner settings to reduce energy consumption

Turning off machines and lights when not in use to save on energy

Geothermal bore for swimming pool heating energy reductions Solar panels

'Waterwise' Aquatic centre (see utility revolving fund above)

90\% paper reduction and increased customer service through an online application tool and paper reduction communication processes bore, Utility Revolving Fund, solar expansion, staff hiring etc., that would lead to resource savings and program delivery that are still today being sustained."

Examples of these initiatives are given in Table 3 below:

\section{Discussion}

Given that there was no sustainability program in 2011, a lot was achieved in advancing sustainability within the organisation over the following 5 years-as evidenced by the sustainability initiatives in Table 3. In August 2016, an independent consultant was commissioned to prepare a summary report of sustainability at the City and wrote that, "the capacity building approach leverages action and results for sustainability across different departments and functions through the training and development of 70 Sustainability Champions and 21 Sustainability Representatives, across 21 Departments. This network effectively multiplies the impact of the sustainability team in a way that could not realistically be replicated through the addition of staff in the team' (McManus 2016). 
All survey respondents were positive about the program and examples can be added to the assessment made by McManus (2016). Some survey responses related the policy to the education and training,

"Without these first steps of education and training, it would not have gained the traction required to get it moving. The policy was crucial and beginning the establishment of sustainability in the city. The policy found its way into Council Reports and Business Unit Plans. It became front and centre in day to day management of the business."

But perhaps the most common response related to the empowering nature of the sustainability mandate, the invitation to become change agents with a network of colleagues and access to education and support to do this. In some sense, the training becomes invisible, yet we argue it was central to the actions that followed, for creating the conditions for change, for changing the intent of the organisation. Using the FSSD as the foundation, the training set a common language, a framework for action and defined sustainability as a boundary object within which officers were challenged to define actions to enable a transition to occur, both within the organisation but also in the broader local government community.

"...the program created the conditions for initiatives and projects to emerge with less opposition or even support at a time where projects were often rejected and not supported. In this sense the period was very much establishing, setting up and embedding. This was the accomplishment and impact."

This supports Fischer and Reicher's "chains of leverage" (2019, p. 4) concept which describes the interaction across the interventions and how one type of change can precipitate another, and the impact this can have on embedding sustainability change into organisational systems and culture. Participatory, collaborative approaches that allow people to collectively create the futures they want to support can build powerful alliances due to a strong sense of shared purpose.

"To me it is not necessarily the individual or chosen tactics that had the biggest effect but rather that these were highly visible, broadly consulted and wide reaching. It seems that this is what gave the sustainability program the foundations it needed to endure in turbulent times then and the times that followed (in another round of institutional change in 2016/17/18). This visibility and embedded approach were effective in normalising sustainability objectives, bringing it to front of mind for many staff thus creating the conditions for sustainability to be an acceptable community and business priority."
Bureaucratic ethnographers Bernstein and Mertz (2011) explore the intersection of human agency and change in the everyday lifeworlds of bureaucrats: "Indeed, in terms of their effects on the everyday life that anthropologists care about, the point-like rulings handed down by courts and the staccato tap of legislative enactments can't compare to the ongoing work of creating and implementing regulations (of land use or of emissions, for example) or of wilfully neglecting and ignoring those regulations, keeping up services (like garbage collection) and structures (like bridges) or letting them stumble and crumble, following through with promised projects (for creating parks or paving roads) or forgetting about them." (Bernstein and Mertz 2011, p. 7).

In this case study, the sustainability movement emerged from within the organisation by an officer who initiated a conversation. This case study describes a process by listing sequential events and steps that brought about change, but equally it describes the actions of individual change agents. The importance of individual characteristics or competencies to lead sustainability change are acknowledge by many sustainability educational researchers (e.g. Wiek et al. 2011), as well as leadership theories that propose that it is less the what or the how of the change, but the who-the "intervenor" that is the essential factor in leading change (Scharmer 2007; Scharmer and Yukelson 2015; Senge et al. 2005). This sentiment is captured in the feedback:

"Although I agree that the 'education'/'learning' was key in the success of moving the organisation towards a more sustainable culture, I do think that a key component is the driving force, YOU! The effectiveness of the training and the champions was dependent on the success of the person driving it."

Although not within the scope of this account, this is an indicator for future research needed. However, this case study does demonstrate that under the right circumstances, and with supportive enabling leadership (Uhl-Bien et al. 2007) change for sustainability can originate from anywhere.

In this case study, embedding organisational sustainability was a co-ordinated process that had the education of individuals within the bureaucracy at its heart. The focus of this social and organisational learning intervention was on "facilitating and moderating learning processes rather than teaching" (Barth and Michelsen 2013, p. 112). The staff's existing positions provided the agency to act on this knowledge. Education was the key leverage point, while a strategic, systematic and holistic sustainability framework (in this case the FSSD) created a shared understanding (boundary object) to guide sustainability changes (Barth and Michelsen 2013), encouraging staff to think outside their disciplinary and bureaucratic silos, to discuss the interconnections with other departments, and create " ... learning environments in 
which such shared understandings can be developed collaboratively" (Barth and Michelsen 2013, p. 114).

\section{Conclusions}

The City of Canning case study demonstrates that educational programs within institutions have the potential to be powerful catalysts for change and considerable impact can occur within a relatively short timeframe. Building capacity and empowering staff amplifies impact. In this case, it would be very unlikely that even with the very best efforts a small sustainability team could have the same impact as 70 Sustainability Champions. Investment in an education program to shift culture was a powerful leverage point that has had, and continues to exert, considerable positive sustainability impact within this large municipality.

The evaluation survey highlights the importance of the internalised sustainability program and education process to build knowledge and capacity within the staff. The education process was coupled with a mandate for the Sustainability Champions to seek out opportunities for improvements. These internal 'change agents' were supported by the Sustainability Team, enabling leaders, but also each other, creating a culture of collaborative learning with a network of likeminded officers and supported through a designed program of activities, events and meetings.

The internal shift towards increased sustainability may not be easily 'seen' by those outside the opaque monolith of the administration; however, it can be witnessed in the many sustainability initiatives that resulted from this internal sustainability program. Many local government actors worked together to embed sustainability into Canning. The key message of this paper is that even within apparently rigid bureaucratic structures such as government departments, bureaucrats have agency. In this case study the agency and initiative for embedding sustainability originated not from a Mayor or politicians, but from officers within the administration-boundary spanners and change agents—-the humans in the system.

Acknowledgements Open access funding provided by Blekinge Institute of Technology. The authors would like to thank James Ayers, Merlina Missimer, John Bryant, Melanie Bainbridge and Clare Barnes for conversations and feedback on earlier drafts of this paper which helped clarify language and thinking. Much gratitude to the current and former staff of the City of Canning who provided their insight and experience through the survey responses, and inspiration over the years through their willingness to learn and work towards a more sustainable world together. Finally, thanks must also go to two anonymous reviewers for their insightful feedback that improved the clarity and accuracy of this article.

Open Access This article is licensed under a Creative Commons Attribution 4.0 International License, which permits use, sharing, adaptation, distribution and reproduction in any medium or format, as long as you give appropriate credit to the original author(s) and the source, provide a link to the Creative Commons licence, and indicate if changes were made. The images or other third party material in this article are included in the article's Creative Commons licence, unless indicated otherwise in a credit line to the material. If material is not included in the article's Creative Commons licence and your intended use is not permitted by statutory regulation or exceeds the permitted use, you will need to obtain permission directly from the copyright holder. To view a copy of this licence, visit http://creativecommons .org/licenses/by/4.0/.

\section{References}

Abson DJ, Fischer J, Leventon J, Newig J, Schomerus T, Vilsmaier $\mathrm{U}$, von Wehrden $\mathrm{H}$, Abernethy P, Ives CD, Jager NW, Lang DJ (2017) Leverage points for sustainability transformation. Ambio 46:30-39. https://doi.org/10.1007/s13280-016-0800-y

Barth M (2015) Implementing sustainability in higher education: learning in an age of transformation. Routledge, Abingdon

Barth M, Michelsen G (2013) Learning for change: an educational contribution to sustainability science. Sustain Sci 8:103-119. https:// doi.org/10.1007/s11625-012-0181-5

Bernstein A, Mertz E (2011) Introduction bureaucracy: ethnography of the state in everyday life. PoLAR Polit Legal Anthropol Rev 34:6-10. https://doi.org/10.1111/j.1555-2934.2011.01135.x

Bögel P, Pereverza K, Upham P, Kordas O (2019) Linking socio-technical transition studies and organisational change management: steps towards an integrative, multi-scale heuristic. J Clean Prod 232:359-368. https://doi.org/10.1016/j.jclepro.2019.05.286

Broman GI, Robèrt K-H (2017) A framework for strategic sustainable development. J Clean Prod 140:17-31. https://doi.org/10.1016/j. jclepro.2015.10.121

Brundtland GH (1987) Our common future-call for action. Environ Conserv 14:291-294. https://doi.org/10.1017/S03768929000168 05

Bryant J (2012) Being human in the system: a journey into sustainability and local government in Perth, Western Australia

Fischer J, Riechers M (2019) A leverage points perspective on sustainability. People Nat 1:115-120. https://doi.org/10.1002/pan3.13

Government of Western Australia (1995) Western Australian Legislation-local government act [WWW document]. https://www.legis lation.wa.gov.au/legislation/statutes.nsf/main_mrtitle_551_homep age.html. Accessed 20 Oct 2019

Lang DJ, Wiek A, Bergmann M, Stauffacher M, Martens P, Moll P, Swilling M, Thomas CJ (2012) Transdisciplinary research in sustainability science: practice, principles, and challenges. Sustain Sci 7:25-43. https://doi.org/10.1007/s11625-011-0149-x

Lotz-Sisitka H, Wals AE, Kronlid D, McGarry D (2015) Transformative, transgressive social learning: rethinking higher education pedagogy in times of systemic global dysfunction. Curr Opin Environ Sustain Sustain Sci 16:73-80. https://doi.org/10.1016/j. cosust.2015.07.018

Lyles MA (2014) Organizational learning, knowledge creation, problem formulation and innovation in messy problems. Eur Manag J 32:132-136. https://doi.org/10.1016/j.emj.2013.05.003

Macintyre T, Lotz-Sisitka H, Wals A, Vogel C, Tassone V (2018) Towards transformative social learning on the path to 1.5 degrees. Curr Opin Environ Sustain 31:80-87. https://doi.org/10.1016/j. cosust.2017.12.003

McManus M (2016) Business development for sustainability and the canning river eco-education centre-unpublished 
Meadows DH, Wright D (2009) Thinking in systems [elektronisk resurs]: a primer. Earthscan, London

Meyer JHF, Land R (2005) Threshold concepts and troublesome knowledge (2): epistemological considerations and a conceptual framework for teaching and learning. High Educ 49:373-388. https://doi.org/10.1007/s10734-004-6779-5

Mezirow J (1997) Transformative learning: theory to practice. New Dir Adult Contin Educ 1997:5. https://doi.org/10.1002/ace.7401

Miller TR, Wiek A, Sarewitz D, Robinson J, Olsson L, Kriebel D, Loorbach D (2014) The future of sustainability science: a solutions-oriented research agenda. Sustain Sci 9:239-246. https://doi. org/10.1007/s11625-013-0224-6

Missimer M, Connell T (2012) Pedagogical approaches and design aspects to enable leadership for sustainable development. Sustain J Rec 5:172-181. https://doi.org/10.1089/SUS.2012.9961

Perez Salgado F, Abbott D, Wilson G (2018) Dimensions of professional competences for interventions towards sustainability. Sustain Sci 13:163-177. https://doi.org/10.1007/s11625-017-0439-z

Rieckmann M (2012) Future-oriented higher education: which key competencies should be fostered through university teaching and learning? Futures 44:127-135. https://doi.org/10.1016/j.futur es.2011.09.005

Robèrt K-H, Schmidt-Bleek B, Aloisi de Larderel J, Basile G, Jansen JL, Kuehr R, Price Thomas P, Suzuki M, Hawken P, Wackernagel M (2002) Strategic sustainable development-selection, design and synergies of applied tools. J Clean Prod 10:197-214. https:// doi.org/10.1016/S0959-6526(01)00061-0
Scharmer CO (2007) Theory U : leading from the future as it emerges: the social technology of presencing. Society for Organizational Learning, Cambridge, Mass

Scharmer O, Yukelson A (2015) Theory U: from ego-system to ecosystem economies. J Corp Citiz 58:35-39

Senge P, Scharmer OC, Jaworski J, Flowers BS (2005) Presence: exploring profound change in people, organizations, and society. Nicholas Brealey, London

Uhl-Bien M, Marion R, McKelvey B (2007) Complexity leadership theory: shifting leadership from the industrial age to the knowledge era. Leadersh Q Leadersh Complex 18:298-318. https://doi. org/10.1016/j.leaqua.2007.04.002

Waddell S, Waddock S, Cornell S, Dentoni D, McLachlan M, Meszoely $G$ (2015) Large systems change: an emerging field of transformation and transitions. J Corp Citiz 58:5-30

Western Australia (ed) (2003) Hope for the future: the Western Australian state sustainability strategy-year one progress report 2004. Department of the Premier and Cabinet, Perth, WA

Wiek A, Withycombe L, Redman CL (2011) Key competencies in sustainability: a reference framework for academic program development. Sustain Sci 6:203-218. https://doi.org/10.1007/s1162 5-011-0132-6

Yin RK (2013) Case study research: design and methods. SAGE Publications, New York

Publisher's Note Springer Nature remains neutral with regard to jurisdictional claims in published maps and institutional affiliations. 